\title{
Syringobulbia associated with posterior fossa meningioma: a review of the literature
}

\author{
Mattia Del Maestro • Danilo De Paulis • \\ Alessandro Ricci • Francesco Di Cola • Renato Galzio
}

Received: 18 May 2014 / Accepted: 23 May 2014 / Published online: 5 June 2014

(C) Springer-Verlag Berlin Heidelberg 2014

\begin{abstract}
Purpose Syringomyelia can be defined as a degenerative, progressive and chronic spinal cord disease. Its association with tumors of the posterior cranial fossa (PCF) is a rare condition.

Methods The authors report a rare case of syringobulbia consequent to a meningioma originating from PCF in a 17-yearold female, discussing the pathogenetic mechanism of development and the resolution of the syrinx cavity after surgical procedure.

Results The postoperative period was uneventful without complications. At 6-month follow-up, MRI revealed complete tumor removal with resolution of the syrinx cavity.

Conclusions In cases of syringomyelia and tonsillar herniation associated with PCF meningioma, the tumor resection allows to eliminate the mass effect and increases the size of the posterior fossa with the progressive ascent of the cerebellar tonsils and the consequent reduction of their downward movement with systolic pulsation. The re-establishment of a normal anatomical condition led to the gradual disappearance of syrinx and hydrocephalus.
\end{abstract}

Keywords Syringomyelia $\cdot$ Posterior cranial fossa . Meningioma $\cdot \mathrm{CSF}$ circulation

M. Del Maestro $\cdot$ F. Di Cola $\cdot$ R. Galzio

Department of Life, Health \& Environmental Sciences (Me.S.V.A.),

University of L'Aquila, L'Aquila, Italy

D. De Paulis $(\bowtie) \cdot$ A. Ricci

Department of Neurosurgery, "San Salvatore" City Hospital,

L'Aquila, Italy

e-mail: d.depaulis@alice.it

\section{Introduction}

The syringomyelic cavity is a degenerative, progressive, and chronic spinal cord disease. Sometimes, the cavity may extend at the level of the medulla oblongata, causing a syringobulbia [22]. Syringomyelia is most commonly secondary to a Chiari malformation [22]. Its association with tumors of the posterior cranial fossa (PCF) is a rare condition, with few cases described in literature of epidermoids [11,27], medulloblastomas [21, 28], gliomas [28], metastases [28], synovialomas [21], cysts [3, 5, 8, 10, 18, 29, 35], gangliocytomas [24], dysembryoplastic tumors [34], and meningiomas (Table 1) $[2,6,7,9,12,13,19-21,28]$

The authors present a case of syringobulbia secondary to a meningioma of the PCF, reviewing the pertinent literature and discussing surgical management and the potential pathogenetic mechanism.

\section{Case report}

A 17 year-old female, with recurrent episodes of dizziness, paresthesia in left trigeminal regions, and headaches, from 1 month, began to suffer from neck pain, loss of balance, numbness, and dysesthesia in the upper limbs. She presents a horizontal right gaze-evoked nystagmus, left hearing loss, and left swinging at the Romberg's test. Brain and spinal magnetic resonance imaging (MRI) revealed a large left sighted extra-axial tumor in the PCF, associated with supratentorial hydrocephalus. The cerebral tonsils were herniated down through the foramen magnum, and a syrinx was centrally located from medulla oblongata to C7 (Fig. 1).

The patient underwent to a left retrosigmoid craniectomy with total tumor resection. The histopathological diagnosis was a fibrous meningioma (WHO grade 1). 

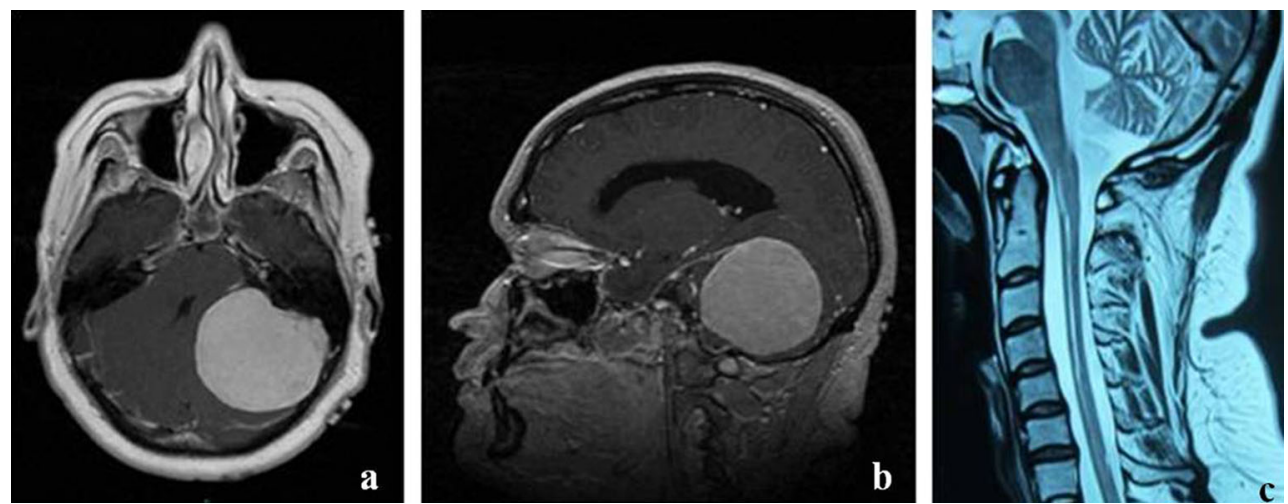

Fig. 1 Preoperative brain MRI in axial (a) and sagittal (b) T1-weighted images with Gadolinium, revealed a left sighted extra-axial tumor in the PCF, originating from the petrous bone, measuring $6 \times 5 \times 6.5 \mathrm{~cm}$; the preoperative cervico-dorsal MRI in sagittal T2-weighted image showed cerebral tonsils herniated down through the foramen magnum and a syrinx from medulla oblongata to $\mathrm{C} 7$ (c)

The postoperative period was uneventful without complications. At 6-month follow-up, MRI revealed complete tumor removal with resolution of the syrinx cavity (Fig. 2).

\section{Discussion}

From 1993 to 2013, only ten reports, accounting for a total of 11 meningiomas of the PCF associated with tonsillar herniation and syringomyelia, have been described in literature $[2,6$, $7,12,13,19-21,28]$. The average age of the patients is 42 years with the female prevalence of 10:1. In range of solid tumors, meningiomas are the majority of them $[2,6,7,12,13$, 19-21, 28], but no cases of syringobulbia associated with meningioma has been reported (Table 1).

There are three distinct groups of cavities in the spinal cord $[16,17]$. The hydromyelic or communicating form that is centrally located within the cord and opens rostrally into the fourth ventricle. The second form is the syringomyelic or noncommunicating, where the rostral end of the cavity is closed below its opening into the fourth ventricle [25]. The third form, named as extracanalicular syrinx, is secondary to a spinal cord injury [2].

The large majority of modern investigators believe that the pathogenesis of syringomyelia associated with a lesion in the

Fig. 2 Postoperative brain MRI in axial (a) and sagittal (b) T1weighted images showed the complete removal of the tumor; the postoperative cervico-dorsal MRI in sagittal T2-weighted image showed, after 6 months, the complete resolution of the syrinobulbia (c)

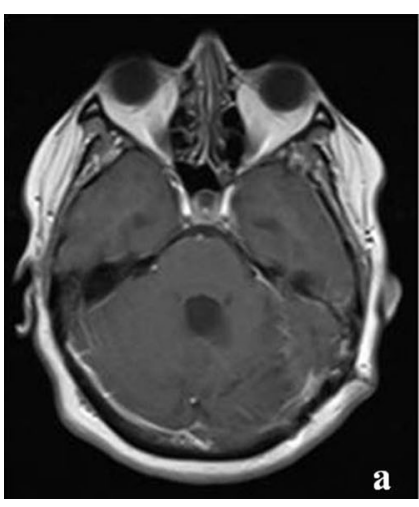

$\mathrm{PCF}$ is related to a disturbance in the circulation of the cerebrospinal fluid (CSF).

Gardner [14] proposed that a congenital defect in the fourth ventricle would cause abnormal pulsations of the CSF directed into the central canal, causing hydromyelia.

Williams [30-33] postulated that an obstruction of the subarachnoid space at the foramen magnum could act as a valve, allowing CSF to cross the foramen magnum rostrally more effectively than caudally. Activities, such as coughing, could cause prolonged elevation of intracranial CSF pressure relative to intraspinal CSF pressure. During this period of "craniospinal dissociation," CSF may be "sucked" from the fourth ventricle into the central canal [22]. A major problem with these hydrodynamical theories is the claim that the source of syrinx fluid is CSF entering the central canal from the fourth ventricle.

Detailed neuropathological investigations [16, 25] have shown that communication of the syrinx with the fourth ventricle occurs only in the hydromyelic form. As a result, several theories have been proposed, all of which assert that the source of syrinx fluid in the noncommunicating form of syringomyelia is the CSF in the spinal subarachnoid space [22].

Ball and Dayan [4] emphasized the importance of activities that increase thoracic or abdominal pressure. These increase epidural venous pressure and spinal CSF pressure. The spinal
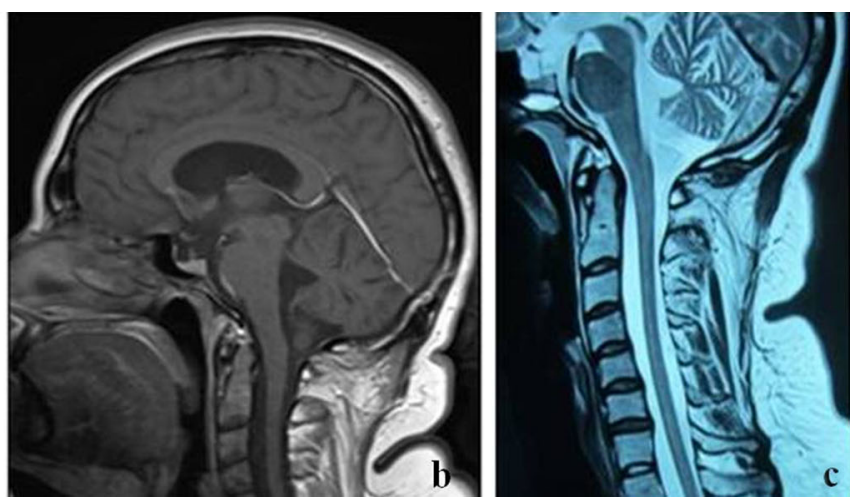
Table 1 Review of the literature of PCF meningiomas with syringomyelia

\begin{tabular}{|c|c|c|c|c|c|c|c|c|c|}
\hline Authors & $\begin{array}{l}\text { Age/ } \\
\operatorname{sex}\end{array}$ & $\begin{array}{l}\text { Dimension } \\
(\mathrm{cm})\end{array}$ & $\begin{array}{l}\text { Tumor } \\
\text { sympt. }\end{array}$ & $\begin{array}{l}\text { Syrinx } \\
\text { sympt. }\end{array}$ & $\begin{array}{l}\text { Duration } \\
\text { of sympt. }\end{array}$ & $\begin{array}{l}\text { MR-syrinx/ } \\
\text { hydrocephalus }\end{array}$ & Syringobulbia & Surgery & Syrinx follow-up \\
\hline Fukui 1993 & $66 / \mathrm{F}$ & NA & + & - & 3 years & $\mathrm{C} 2-\mathrm{C} 4 / \mathrm{NA}$ & - & $\mathrm{RC}$ & Reduction at 2 months \\
\hline Klekamp 1995 & $17 / \mathrm{M}$ & NA & NA & NA & NA & $\mathrm{Cervical}^{\mathrm{a}} / \mathrm{NA}$ & - & VP shunt, tumor resection & Reduction at 2 months \\
\hline \multirow[t]{2}{*}{ Tachibana 1995} & $53 / \mathrm{F}$ & NA & + & - & 3 years & Cervical $^{\mathrm{a} /+}$ & - & NA & Reduction \\
\hline & $50 / \mathrm{F}$ & NA & + & - & NA & Cervical $^{\mathrm{a} /+}$ & - & NA & NA \\
\hline Anegawa 1997 & $36 / F$ & NA & + & - & 3 months & Cervical $^{\mathrm{a}} / \mathrm{NA}$ & - & NA & Reduction at 3 months \\
\hline $\begin{array}{l}\text { Jaiswal and } \\
\text { Chandra } \\
2001\end{array}$ & $30 / \mathrm{F}$ & NA & + & + & 5 years & Cervical $^{\mathrm{a} /+}$ & - & $\mathrm{RC}$ & NA \\
\hline Karttunen 2002 & $34 / \mathrm{F}$ & 5 & + & - & NA & C2-T2/- & - & Suboccipital craniectomy & Reduction at 22 months \\
\hline Bhatoe 2004 & $38 / \mathrm{F}$ & NA & + & - & 6 month & Cervical $^{\mathrm{a} /+}$ & - & $\mathrm{RC}$ & Resolution at 3 months \\
\hline Fox 2005 & $53 / \mathrm{F}$ & $4 \times 4,5$ & + & - & 6 months & C2-C6/+ & - & $\mathrm{RC}$ & Resolution at 1 year \\
\hline Bouras 2005 & $55 / \mathrm{F}$ & $4 \times 4$ & + & + & 6 years & $\mathrm{C} 1-\mathrm{C} 4 /-$ & - & Suboccipital craniectomy & Reduction at 1 year \\
\hline Present case & $17 / \mathrm{F}$ & $6 \times 5 \times 6,5$ & + & + & 3 years & $\mathrm{C} 0-\mathrm{C} 7 /+$ & + & $\mathrm{RC}$ & Resolution at 6 months \\
\hline
\end{tabular}

$N A$ information not available, $V P$ ventriculoperitoneal, Sympt symptoms, $R C$ retromastoid craniectomy

${ }^{\text {a }}$ Extent of syrinx not reported

CSF, instead of entering the intracranial subarachnoid space, cannot cross the foramen magnum because of the obstruction; so, it is diverted into the spinal cord parenchyma along Virchow-Robin spaces [22].

Aboulker [1] proposed that obstruction at the foramen magnum interferes with intracranial drainage of the CSF produced in the spinal cord and nerve roots.

Heiss et al., Levy et al., and Oldfield et al. [15, 23, 26] proposed that the force impelling spinal subarachnoid CSF into the cord parenchyma is the CSF pressure pulsation occurring during the cardiac cycle. When cerebellar tonsils obstruct the foramen magnum, the amount of CSF crossing this one decreases. The tonsils themselves move caudally during systole, cranially during diastole and acting like a piston on the spinal subarachnoid CSF, producing in it exaggerated pulsations. The high-amplitude pulsations drive CSF into the cord along perivascular spaces.

Recently, Levine [22] proposed a new theory applicable to the noncommunicating form of syringomyelia associated with a lesion at the foramen magnum. He considers that the source of the syrinx fluid is a plasma filtrate from the capillaries of the spinal cord. In fact, CSF pressure just rostral to the block exceeds CSF pressure caudal to the block producing changes in transmural venous pressure, which favor dilation of capillaries below the block and collapse of the capillaries above the block. This change is a source of mechanical stress on the spinal cord. Repeated stress over a prolonged period produces partial breakdown of the blood-spinal cord barrier, allowing plasma filtration and accumulation of fluid in the damaged spinal cord.

According to Fox and Oldfield, syringomyelia is a tertiary phenomenon that follows blockage of CSF flow at the foramen magnum. A meningioma in PCF, large and slowly growing, can determine chronic cerebellar tonsils herniation, causing a tightness of the foramen magnum and an obstruction of the subarachnoid space. The result is that the CSF could not normally pass through Luschka and Magendie's foramina with increase of CSF pressure in the fourth ventricle, and the tonsils, in their new pathological position, move downward with systolic increase in pressure. The pressure waves compress the spinal cord and have the potential to propel the syrinx fluid downward with each pulsating beat, thereby increasing the flow between the spinal CSF and the extracellular fluid of the spinal cord $[12,26]$. This mechanism also may be responsible for the maintenance of syringomyelia by the pulsatile pressure waves forcing CSF into the spinal cord through perivascular and interstitial spaces [4]. The compression of the spinal cord exerted by spinal CSF causes rostral and caudal movements of the fluid within the syrinx and could extend the length of the syrinx via a sloshing mechanism [26]. Repeated rostral movement, acting for a long time, then leads to the formation of syringobulbia producing the relative neurological dysfunctions.

In conclusion, in cases of syringomyelia and tonsillar herniation associated with PCF meningioma, the tumor resection eliminates the mass effect and increases the size of the posterior fossa with the progressive ascent of the cerebellar tonsils and the consequent reduction of their downward movement with systolic pulsation. Therefore, the tonsil impaction at the foramen magnum is diminished as the subarachnoid space obstruction, and CSF can flow following his physiological pathway. The re-establishment of a normal anatomical condition led to the gradual disappearance of syrinx and hydrocephalus $[2,6,7,12,13,19-21,28]$. 


\section{References}

1. Aboulker J (1979) La syringomyelie et les liquides intra-rachidiens. Neurochirurgie 25(Suppl):1-144

2. Anegawa S, Hayashi T, Torigoe R, Iwaisako K, Higa-shioka H (1997) Cerebellopontine angle meningioma causing asymptomatic syringomyelia-case report. Neurol Med Chir (Tokyo) 37:624-626

3. Arunkumar MJ, Korah I, Chandy MJ (1998) Dynamic CSF flow study in the pathophysiology of syringomyelias associated with arachnoid cysts of the posterior fossa. Br J Neurosurg 12:33-36

4. Ball MJ, Dayan AD (1972) Pathogenesis of syringomyelia. Lancet 2: 799-801

5. Banna M (1988) Syringomyelia in association with posterior fossa cysts. AJNR Am J Neuroradiol 9:867-873

6. Bhatoe HS (2004) Tonsillar herniation and syringomyelia secondary to a posterior fossa tumor. Br J Neurosurg 18:70-71

7. Bouras TI, Kouyialis T, Boviatsis EJ, Sakas DE (2006) Symptomatic syringomyelia secondary to clinically obscure infratentorial tumour. Br J Neurosurg 20(1):48-50

8. Cano G, Anderson M, Kutschback P, Borden J, Saris S (1993) Hydromyelia associated with a posterior fossa cyst. Surg Neurol 40:512-515

9. Cohen L, Macrae D (1962) Tumors in the region of the foramen magnum. J Neurosurg 19:462-469

10. Conti C, Lungardi P, Bozzao A, Liccardo G, Fraioli B (2003) Syringomyelia associated with hydrocephalus and Blake's pouch cyst: case report. Spine 28:E279-E283

11. D’Osvaldo DH, Otero JM, Mosconi JB, Oviedo JD (2002) Regression of symptomatic syringomyelia after resection of posterior fossa tumor. Acta Neurochir (Wien) 144:385-388

12. Fox B, Muzumdar D, De Monte F (2005) Resolution of tonsillar herniation and cervical syringomyelia following resection of a large petrous meningioma: case report and review of literature. Skull Base 15:89-98

13. Fukui K, Kito A, Iguchi I (1993) Asymptomatic syringomyelia associated with cerebellopontine angle meningioma. Neurol Med Chir (Tokyo) 33:833-835

14. Gardner WJ (1965) Hydrodynamic mechanism of syringomyelia: its relationship to myelocele. J Neurol Neurosurg Psychiatry 28:247-259

15. Heiss JD, Patronas N, DeVroom HL, Shawker T, Ennis R, Kammerer W et al (1999) Elucidating the pathophysiology of syringomyelia. J Neurosurg 91:553-562

16. Hinokuma K, Ohama E, Oyanagi K, Kakita A, Kawai K, Ikuta F (1992) Syringomyelia: a neuropathological study of 18 autopsy cases. Acta Pathol Jpn 42:25-34

17. Hoffman J (1893) Zur Lehre der Syrimgomyelie. Dtsch Z Nervenheilkd 3:1-136

18. Jain R, Sawlani V, Phadke R, Kumar R (2000) Retrocerebellar arachnoid cyst with syringomyelia: a case report. Neurol India 48:81-83
19. Jaiswal AK, Chandra PS (2001) Cerebellopontine angle meningioma with acquired Chiari and syringomyelia: neuroimage. Neurol India 49:323

20. Karttunen A, Heikkinen E, Tuominen J, Jartti P (2002) Secondary syringomyelia disappearing after removal of tentorial meningioma. Acta Neurochir (Wien) 144:741-742

21. Klekamp J, Samii M, Tatagiba M, Sepehrnia A (1995) Syringomyelia in association with tumors of the posterior fossa. Pathophysiological considerations, based on observation on three related cases. Acta Neurochir (Wien) 137:38-43

22. Levine DN (2004) The pathogenesis of syringomyelia associated with lesions at the foramen magnum: a critical review of existing theories and proposal of a new hypothesis. J Neurol Sci 220:3-21

23. Levy EI, Heiss JD, Kent MS, Riedel CJ, Oldfield EH (2000) Spinal cord swelling preceding syrinx development. J Neurosurg 92(Spine 1):93-97

24. Marcus CD, Galeon M, Peruzzi P et al (1996) Lhermitte-Duclos disease associated with syringomyelia. Neuroradiology 38:529531

25. Milhorat TH, Capocelli AL Jr, Anzil AP, Kotzen RM, Milhorat RH (1995) Pathological basis of spinal cord cavitation in syringomyelia: analysis of 105 autopsy cases. J Neurosurg 82:802-812

26. Oldfield EH, Muraszko K, Shawker TH, Patronas NJ (1994) Pathophysiology of syringomyelia associated with Chiari I malformation of the cerebellar tonsils. J Neurosurg 80:3-15

27. Sgaramella E, Perria C (1996) Regression of syringomyelia after removal of a posterior fossa epidermoid tumor. Br J Neurosurg 10: 409-411

28. Tachibana S, Harada K, Abe T, Yamada H, Yokata A (1995) Syringomyelia secondary to tonsillar herniation caused by posterior fossa tumors. Surg Neurol 43:470-477

29. Tokime T, Okamoto S, Yamagata S, Konishi T (1997) Syringomyelia associated with a posterior fossa cyst. Illustration of two cases. J Neurosurg 86:907

30. Williams B (1969) The distending force in the production of "communicating syringomyelia". Lancet 2:189-193

31. Williams B (1970) Current concepts of syringomyelia. Br J Hosp Med 4:331-342

32. Williams B (1977) On the pathogenesis of the Chiari malformation. Z Kinderchir Grenzgeb 22:533-553

33. Williams B (1981) Simultaneous cerebral and spinal fluid pressure recordings: 2. Cerebrospinal dissociation with lesions at the foramen magnum. Acta Neurochir 59:123-142

34. Yasha TC, Mohanty A, Radhesh S, Santosh V, Das S, Shankar SK (1998) Infratentorial dysembryoplastic neuroepithelial tumor (DNT) associated with Arnold-Chiari malformation. Clin Neuropathol 17: 305-310

35. Zager EL, Ojemann RG, Poletti CE (1990) Acute presentations of syringomyelia. Report of three cases. J Neurosurg 72: $133-138$ 